\title{
Increased sialylation as a phenomenon in accommodation of the parasitic nematode Trichinella spiralis (Owen, 1835) in skeletal muscle fibres
}

\author{
Rositsa Milcheva ${ }^{1,2}$, Dimitar Ivanov ${ }^{1}$, Ivan Iliev $^{1}$, Russy Russev $^{1}$, Svetlozara Petkova $^{1}$ and Pavel Babál ${ }^{2}$ \\ ${ }^{1}$ Institute of Experimental Morphology, Pathology and Anthropology with Museum, Bulgarian Academy of Sciences, Sofia, Bulgaria; \\ ${ }^{2}$ Department of Pathology, Faculty of Medicine, Comenius University in Bratislava, Bratislava, Slovakia
}

\begin{abstract}
The biology of sialic acids has been an object of interest in many models of acquired and inherited skeletal muscle pathology. The present study focuses on the sialylation changes in mouse skeletal muscle after invasion by the parasitic nematode Trichinella spiralis (Owen, 1835). Asynchronous infection with T. spiralis was induced in mice that were sacrificed at different time points of the muscle phase of the disease. The amounts of free sialic acid, sialylated glycoproteins and total sialyltransferase activity were quantified. Histochemistry with lectins specific for sialic acid was performed in order to localise distribution of sialylated glycoconjugates and to clarify the type of linkage of the sialic acid residues on the carbohydrate chains. Elevated intracellular accumulation of $\alpha-2,3-$ and $\alpha-2,6$-sialylated glycoconjugates was found only within the affected sarcoplasm of muscle fibres invaded by the parasite. The levels of free and protein-bound sialic acid were increased and the total sialyltransferase activity was also elevated in the skeletal muscle tissue of animals with trichinellosis. We suggest that the biological significance of this phenomenon might be associated with securing integrity of the newly formed nurse cell within the surrounding healthy skeletal muscle tissue. The increased sialylation might inhibit the affected muscle cell contractility through decreased membrane ion gating, helping the parasite accommodation process.
\end{abstract}

Keywords: glycosylation, sialic acid, nurse cell

Sialic acids represent more than 40 modifications of the nine-carbon $\mathrm{N}$-acetylneuraminic acid (NANA), which is synthesised from N-acetylmanosamine-6-phosphate and phosphoenolpyruvate in the cytosol. The molecule of NANA is activated in the nucleus by tagging a cytidine monophosphate residue (CMP) and then is translocated to the Golgi apparatus or the endoplasmic reticulum. There, the activated sialic acid can be transferred by a sialyltransferase onto an appropriate acceptor molecule from the oligosaccharide chain of a nascent glycoconjugate via alpha-2,3, $-2,6$ or $-2,8$ glycosidic bond (Traving and Schauer 1998). Sialic acids typically occupy the outermost position of the carbohydrate chains of glycoconjugates in higher animals and some microorganisms (Schauer 2004) and this predetermines their participation in almost all types of recognition processes, receptor interactions and adhesion phenomena (Varki 1997, Schauer 2009). Studies have revealed the importance of the sialic acids in skeletal muscle tissue for the functional maintenance of glycoproteins involved in fibre structure and neuromuscular junctions (McDearmon et al. 2003, Combs and Ervasti 2005), development and regeneration (Broccolini et al. 2008), muscle excitability (Johnson et al. 2004, Schwetz et al. 2011) and exercise performance
(Hanish et al. 2013). So far, the biology of sialic acids has been an object of interest in ageing of skeletal muscles (Hanisch et al. 2013, Marini et al. 2014) and in many models of skeletal muscle pathology, including denervation of muscle (Andrew and Appel 1973, Cotrufo and Appel 1973), myopathy induced by chemical injury and regeneration (Nakamura et al. 2010), and also in inherited myopathies (Tajima et al. 2005, Broccolini et al. 2011). However, information in the available literature is missing about the influence of infectious parasitic agents on the sialylation in their combat for survival particularly in the skeletal muscles.

Trichinellosis results from infection by a parasitic nematode that belongs to the genus of Trichinella Railliet, 1895. The disease starts in the small intestine where nematodes reproduces. The newborn larvae are accommodated only in the skeletal muscle cells where they induce drastic morphological, functional and enzymatic changes after penetrating. The occupied portion of the muscle fibre transforms into a structure called a nurse cell, which is capable of supporting the parasite for years (Capó and Despommier 1996, Despommier 1998).

The process of transformation of skeletal muscle fibre into the nurse cell leads to loss of its contractile properties

Address for correspondence: R. Milcheva, Institute of Experimental Morphology, Pathology and Anthropology with Museum, Bulgarian Academy of Sciences, Acad. G. Bonchev Str., block 25, Sofia 1113, Bulgaria. Phone: 003598866167 90, E-mail: rosicamilcheva@abv.bg 
Table 1. Lectins used in the study, their abbreviations, carbohydrate specificity, applied dilutions and related references.

\begin{tabular}{|c|c|c|c|c|}
\hline Lectin & Abbreviation & Carbohydrate specificity & Dilution & References \\
\hline Maackia amurensis lectin-II & MAL-II & $\operatorname{SiA} \alpha(2,3) \mathrm{Gal} \beta(1,4) \mathrm{GlcNAc}$ & $1: 1000$ & Knibbs et al. 1991 \\
\hline Sambucus nigra agglutinin & SNA & $\operatorname{SiA} \alpha(2,6) \mathrm{Gal} \beta(1,4) \mathrm{GlcNAc} ; \operatorname{Sia} \alpha(2,6)$ GalNAc- $\alpha-\mathrm{O}-\mathrm{Ser} / \mathrm{Thr}$ & $1: 2000$ & Kaku et al. 2007 \\
\hline Tritrichomonas mobilensis lectin & TML & $\mathrm{SiA}$ & $1: 100$ & Babál et al. 1994 \\
\hline
\end{tabular}

$\mathrm{SiA}$ - sialic acid, Gal - galactose, GalNAc - N-acetyl-D-galactosamine.

but still remains integrated within the muscle fibres. Considering the role of sialic acids and their negative electric charge in adhesive mechanisms, we assume that this process may be associated with increased sialylation of the affected skeletal muscle fibres. In the present study we demonstrate increased activity of sialyltransferases and high amounts of sialylated glycoconjugates in skeletal muscle cells associated with experimentally-induced trichinellosis.

\section{MATERIALS AND METHODS}

\section{Parasites, invasion, sample collection and processing}

All animal experiments described in this work were performed in compliance with the Institutional Guidelines for Animal Experiments of IEMPAM - the Bulgarian Academy of Sciences.

Infective larvae of Trichinella spiralis (Owen, 1835) were isolated from previously invaded mice, between $30^{\text {th }}$ and $40^{\text {th }}$ day post infection (d.p.i.) according to a routine protocol (Kapel and Gamble 2000). BALB/C, 6-8 weeks old mice (Mus musculus Linnaeus) were inoculated with 500 infective larvae of $T$. spiralis per os. The animals (3 per group) were sacrificed at $0,10,14$, 16 and 40 d.p.i. Tissue specimens were excised from the pectoral, femoral and gluteal muscles and fixed for $48 \mathrm{~h}$ with $10 \%$ neutral buffered formaldehyde (NBF), with modified methacarn fixative (MMC) containing $8: 1 \mathrm{v} / \mathrm{v}$ methanol and glacial acetic acid (Cox et al. 2006), or were stored at $-80^{\circ} \mathrm{C}$ for several days. After processing and embedding in paraffin, sections $5 \mathrm{~mm}$ thick were routinely stained with hematoxylin and eosin for basic morphological evaluation.

\section{Preparation of rabbit hyperimmune serum against L1 larvae of $T$. spiralis}

The rabbit hyperimmune serum against infectious larvae of T. spiralis was produced according to the routinely-used protocols of IEMPAM-BAS (Komandarev et al. 1986). Crude antigen (Ag) of muscle $T$. spiralis larvae was prepared as already described (Milcheva et al. 2009a). In brief, male California breed rabbits (Oryctolagus cuniculus Linnaeus) were subcutaneously injected with $1 \mathrm{ml}$ compound containing $150 \mu \mathrm{g}$ of $T$. spiralis antigen diluted in saline and Freund's complete adjuvant (Sigma-Aldrich, St. Louis, Missouri, USA). Two further $1 \mathrm{ml}$ inoculations followed with $150 \mu \mathrm{g}$ and $200 \mu \mathrm{g}$ of Trichinella Ag and Freund's incomplete adjuvant at days 14 and 21, respectively. Finally, 250 $\mu \mathrm{g} / \mathrm{ml}$ of protein in saline were inoculated, in the absence of adjuvant, 28 days after the first inoculation and blood was collected 10 days after the last inoculation. Antibody titer against $T$. spiralis antigen was determined through indirect ELISA using anti-rabbit peroxidase conjugate (Bul-Bio, Sofia, Bulgaria) and aliquots of the hyperimmune sera supplemented with $0.01 \% \mathrm{NaN}_{3}(\mathrm{w} / \mathrm{v})$ were stored at $-20^{\circ} \mathrm{C}$.

\section{Histochemistry}

De-paraffinised sections were rehydrated in tris buffered saline (TBS) solution $\mathrm{pH} 7.4$, with or without (in case of fluorescein labelled SNA) $0.1 \%$ Tween 20. Endogenous peroxidase was blocked with EnVison ${ }^{\mathrm{TM}}$ Peroxidase Block (Dako, Glostrup, Denmark). Endogenous biotin was blocked with Biotin blocking system (Dako). The rabbit hyperimmune serum against infectious larvae of $T$. spiralis was diluted in REAL antibody diluents (Dako); the lectins were diluted in TBS pH 7.4.

\section{Immunohistochemistry}

For verification of the sites of occupation, sections from all experimental groups, fixed with NBF and MMC, were treated for $16 \mathrm{~h}$ with rabbit hyperimmune serum against infectious larvae of T. spiralis (1: 5000), then incubated for 30 min with EnVision $^{\mathrm{TM}}$ anti-rabbit polymer conjugated with horseradish peroxidase (Dako) and the peroxidase activity was developed with En Vision $^{\mathrm{TM}}$ 3,3'-diaminobenzidine (DAB+) Substrate-Chromogen (Dako). In parallel, negative control specimens were incubated with REAL antibody diluents (Dako) instead of antibody and thereafter with the corresponding peroxidase conjugate. The sections were counterstained with hematoxylin, mounted in acrylic resin and examined with Nikon Eclipse 80í light microscope (Nikon Engineering Co., Ltd., Yokohama, Japan).

The intracellular staining intensity of the occupied fibres was evaluated semi-quantitatively versus the surrounding non-affected sarcoplasm by two independent observers into two categories: negative (-) and positive (+). The number of invaded fibres was counted in 12 transverse sections of three muscles from each group and their percentage was calculated versus the total number of fibres per section.

\section{Lectin histochemistry with biotinylated lectins}

Parallel tissue sections, $5 \mathrm{~mm}$ thick, were cut from $10 \% \mathrm{NBF}$ materials from all experimental groups and submitted to histochemistry with Sambucus nigra agglutinin (SNA, Vector, Burlingame CA, USA), Maackia amurensis lectin (MAL, Vector) and Tritrichomonas mobilensis lectin (TML, Calbiochem-Novabiochem, San Diego, CA, USA) specific to bind sialic acid residues with different linkage type preferences (Table 1). All tissue sections intended for this part of the study were divided in three groups according to the applied lectin and each group included duplicates of experimental sections, negative controls, sections incubated with previously blocked lectin and neuraminidase pretreated sections (a total of 10 slides per animal). The sections were incubated for 1 hour at room temperature with SNA (1: 2000), MAL $(1: 1000)$ and TML $(1: 100)$. To check the binding specificity, the three lectins were pre-incubated in part of the experiments with $100 \mathrm{mM}$ solutions of 3'-sialyllactose and 6'-sialyllactose (Calbiochem-Novabiochem) for 1 hour at room 
temperature. The incubation with neuraminidase was performed with $0.5 \mathrm{U} / \mathrm{ml}$ of neuraminidase (Sigma-Aldrich) in $50 \mathrm{mM}$ sodium acetate buffer ( $\mathrm{pH} 5.5$ ), at $37^{\circ} \mathrm{C}$ for 15 hours before application of peroxide and biotin blocking systems. In parallel, negative control specimens were incubated with TBS instead of lectin. All of the sections were then treated with streptavidin-HRP (Dako) for $30 \mathrm{~min}$, then processed as already described and examined with Nikon Eclipse 80í light microscope.

The intracellular staining intensity of the invaded fibres was evaluated semi-quantitatively versus the surrounding non-affected sarcoplasm by two independent observers as: negative (-), weak $(+)$, moderate $(++)$ and strong $(+++)$ positive.

Twelve cross sections stained with TML, MAL or SNA were randomly selected from each group and the number of invaded fibres or nurse cells was counted. The average diameter of the muscle fibres was estimated by measuring the diameters of fibres at several different points on each section and the approximate total number of the fibres was calculated, as well as the percentage of the invaded fibres.

\section{Lectin histochemistry with fluorescein-labelled lectin}

Parallel tissue sections, $5 \mathrm{~mm}$ thick, from MMC materials from all experimental groups (at least three sections/animal) were incubated with fluorescein labelled SNA $(1: 2000)$ (Vector) for $1 \mathrm{~h}$ at room temperature in dark. The sections were mounted in water-based medium Fluor Save ${ }^{\mathrm{TM}}$ (Calbiochem-Novabiochem) and immediately examined with UV light in Nikon Eclipse 80í light microscope.

The intracellular staining intensity of the occupied fibres was evaluated semi-quantitatively versus the surrounding non-affected sarcoplasm by two independent observers into two categories: negative (-) and positive (+).

\section{Biochemical analyses}

Approximately $1.3 \mathrm{~g}$ fresh skeletal muscle tissue samples from each mouse included in the study were homogenised on ice in $4 \mathrm{ml}$ ice-cold saline, $\mathrm{pH} 8.6$, supplemented with $1: 8(\mathrm{v} / \mathrm{v})$ protease inhibitor cocktail (Sigma-Aldrich) and centrifuged at $1000 \times \mathrm{g}$ for $15 \mathrm{~min}$. The protein content of the resulted supernatant was measured using Quick Start ${ }^{\mathrm{TM}}$ Bradford Protein Assay (Bio-Rad Laboratories, Hercules, CA, USA) and the samples were used immediately for the following analyses:

\section{Thiobarbituric acid assay of unbound sialic acid}

The level of the unbound sialic acid (four reactions per mouse from each group) was estimated in samples with $1 \mathrm{mg}$ total protein content by the method of Warren (1959), with modification by Aminoff (1961). All chemicals were purchased from Sigma-Aldrich. In brief, the samples were incubated at $37^{\circ} \mathrm{C}$ for 30 min in the presence of $25 \mathrm{mM} \mathrm{NaIO}_{4}$ in $125 \mathrm{mM} \mathrm{H}_{2} \mathrm{SO}_{4}(\mathrm{w} / \mathrm{v})$, then $2 \% \mathrm{Na}_{2} \mathrm{HAsO}_{4} \times 7 \mathrm{H}_{2} \mathrm{O}$ in $500 \mathrm{mM} \mathrm{HCl}(\mathrm{w} / \mathrm{v})$ and $100 \mathrm{mM}$ thiobarbituric acid, $\mathrm{pH} 9.0$, were added. The samples were heated for $15 \mathrm{~min}$ at boiling water bath, the quick cooling step followed and the resulting colour phase was extracted through n-butanol supplemented with $3 \%(\mathrm{v} / \mathrm{v}) \mathrm{HCl}$. The absorption of sialic acid was measured at $549 \mathrm{~nm}$ and also at $532 \mathrm{~nm}$ to eliminate the contribution of 2-deoxyribose. The correction factors for calculations were applied as suggested by Warren (1959), the amount of sialic acid was expressed in terms of nmol sialic acid/mg protein and the values were plotted against the timeline of the experiment. The specificity of the colour reaction was verified in the presence of $1 \mathrm{mg}$ asialofetuin as a negative control and of $1 \mu \mathrm{mol}$ sialic acid as a positive control, instead of a skeletal muscle sample.

\section{Acidic ninhydrin reaction for determination of bound sialic acid in glycoproteins}

The amount of bound sialic acids in glycoproteins (four reactions per mouse from each group) was estimated in samples with $1 \mathrm{mg}$ total protein content by the method of Yao et al. (1989). All chemicals were purchased from Sigma-Aldrich. In brief, the reaction mixture containing one volume glacial acetic acid and one volume $2.5 \%(\mathrm{w} / \mathrm{v})$ ninhydrin solution in glacial acetic acid supplemented with $14.8 \%(\mathrm{v} / \mathrm{v}) \mathrm{HCl}$ was heated for exactly $10 \mathrm{~min}$ in a boiling water bath, the quick cooling step followed, the absorption of sialic acid was measured at $470 \mathrm{~nm}$, and the amount was estimated according to a routinely used standard curve of 0 to $200 \mathrm{nmol}$ sialic acid. The amount of sialic acid was expressed in terms of nmol sialic acid/mg protein and the values were plotted against the timeline of the experiment. The specificity of the colour reaction was verified in the presence of $1 \mathrm{mg}$ asialofetuin as a negative control and of $1 \mathrm{mg}$ fetuin as a positive control, instead of a skeletal muscle sample.

\section{Estimation of total sialyltransferase activity}

The cytidine monophosphate- $\left[{ }^{14} \mathrm{C}\right]-\mathrm{N}$-acetyl neuraminic acid (CMP-[ $\left[{ }^{14} \mathrm{C}\right]-\mathrm{NANA}$ ) was a product of Amersham Biosciences (Amersham, UK) and the rest of the chemicals were purchased from Sigma-Aldrich.

The total activity of sialyltransferases (four reactions per mouse from each group) was estimated in samples with $500 \mu \mathrm{g}$ total protein content by following the transfer of 71.4 pmol CMP$\left[{ }^{14} \mathrm{C}\right]$-NANA, with $3.7 \mathrm{kBq} / \mu 1$ on $300 \mathrm{ng} / \mu 1$ asialofetuin type I, bearing $45 \mathrm{nmol}$ terminal galactose residues. The reaction was performed in the presence of $10 \mathrm{mM} \mathrm{MnCl}_{2}, 0.1 \%$ Triton $^{\mathrm{TM}}$ $\mathrm{x}-100$, and $500 \mathrm{mM}$ maleic acid buffer, $\mathrm{pH} 6.5$, in total volume of $100 \mu 1$ (modification of Sefarini-Cessi 1977). The mixture was incubated at $37^{\circ} \mathrm{C}$ for $30 \mathrm{~min}$ and the reaction was terminated by $1 \mathrm{ml}$ cold $1 \%$ phosphotungstic acid (PTA) in $500 \mathrm{mM} \mathrm{HCl}$. The samples were passed through Whatman ${ }^{R}$ glass microfibre filter grade GF/A (Sigma-Aldrich) and the retained product of the reaction was washed with $50 \mathrm{ml} 1 \%$ PTA- $\mathrm{HCl}$ and $5 \mathrm{ml}$ ether. The filters were then dried and submerged in scintillation solution containing $0.4 \%$ 2,5-diphenyloxazol and $0.015 \%$ 1,4-bis (5-phenyloxazol-2-yl) benzene in toluol, and $\left[{ }^{14} \mathrm{C}\right]$ incorporation was measured as counts per minute c.p.m. by standard liquid scintillation counting. The efficiency of the reaction was verified by the absence of skeletal muscle sample as a source of sialyltranferases; the specificity was verified by the absence of CMP${ }^{14} \mathrm{C}-\mathrm{NANA}$. The estimated c.p.m. indicated the sialyltransferase activity of the sample and the values were plotted as the timeline of the experiment

\section{Statistical analysis}

Statistical evaluation of the data was performed using GraphPad Prism 5.03 software (San Diego, CA, USA). Non-parametric one-way analysis of variance (Kruskal-Wallis test) with Dunn's Multiple Comparison Test (significance level 0.05) was computed to detect statistically significant differences in the yield of 


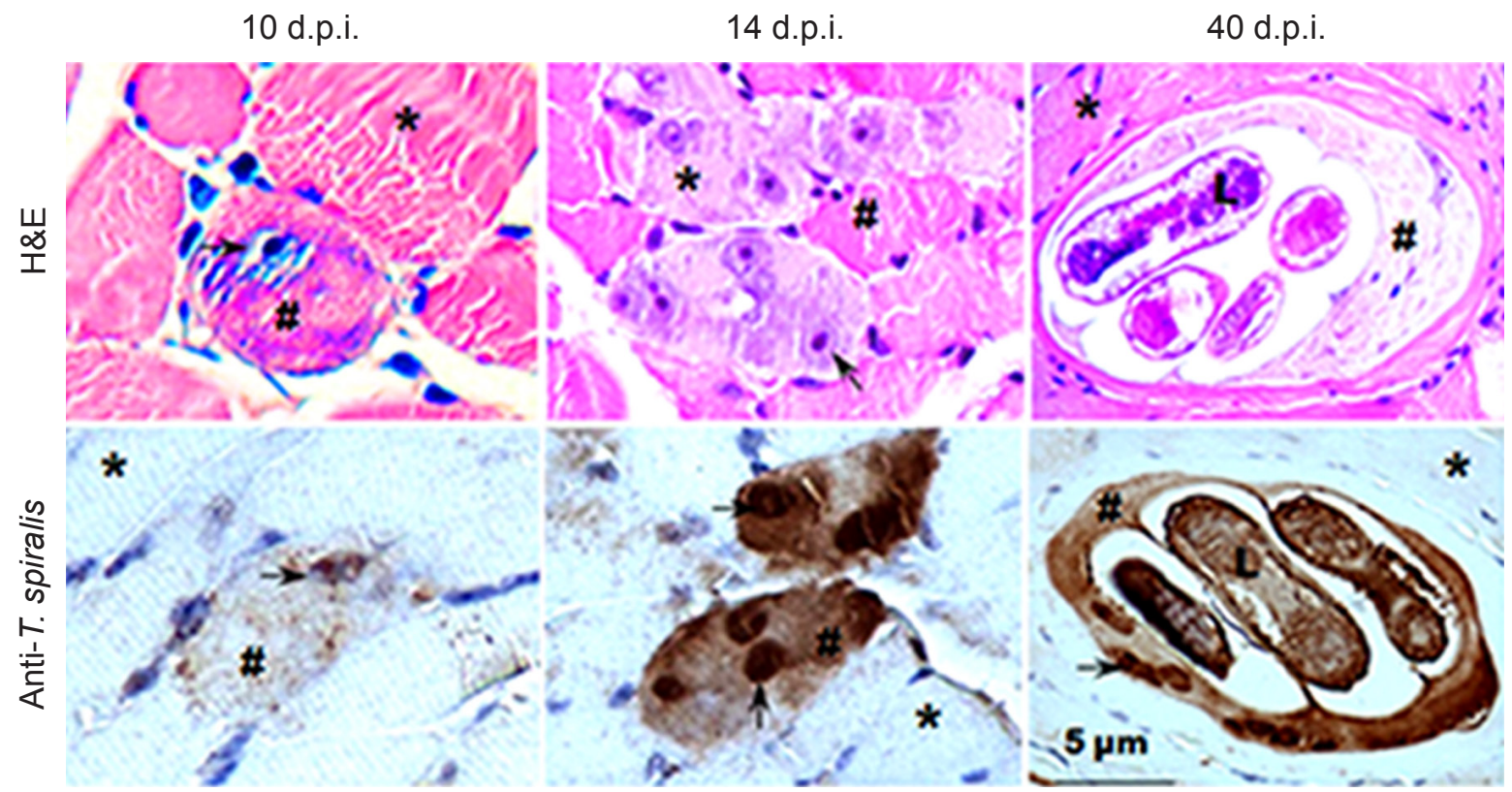

Fig. 1. Basic histology and immunohistochemistry on mouse skeletal muscles with Trichinella spiralis at 10, 14 and 40 days post invasion (d.p.i.). Formalin fixed sections were stained with rabbit hyperimmune serum against infectious larvae of T. spiralis. Note: brown colour - positive histochemical reaction; hash tag - occupied sarcoplasm; star - non-occupied skeletal muscle fibre; arrow - enlarged nucleus; L - larva; H\&E - hematoxylin and eosin. Streptavidin-biotin peroxidase, 3,3'-diaminobenzidine (DAB).

10 d.p.i.
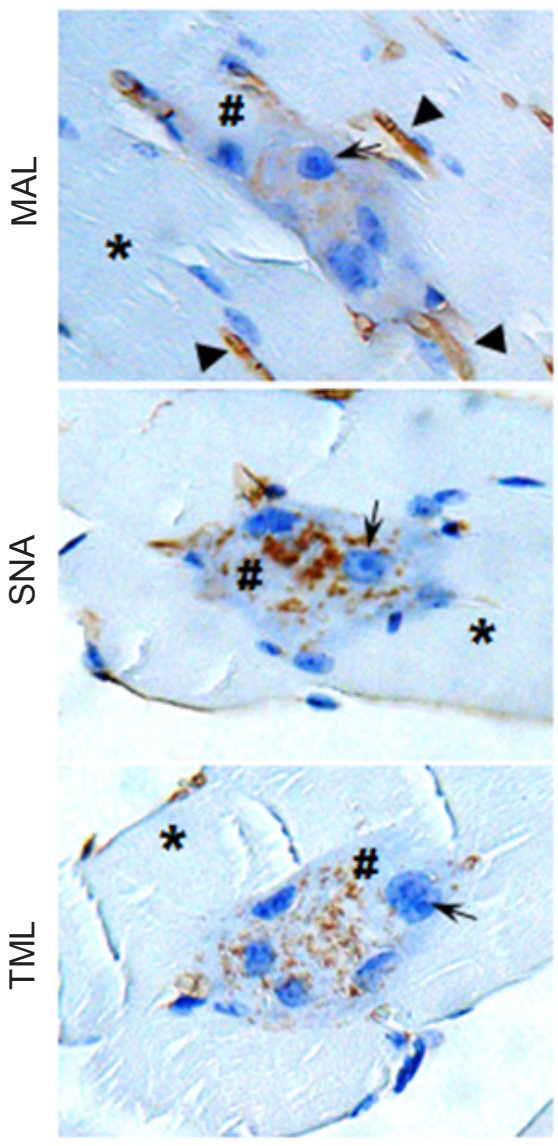

14 d.p.i.
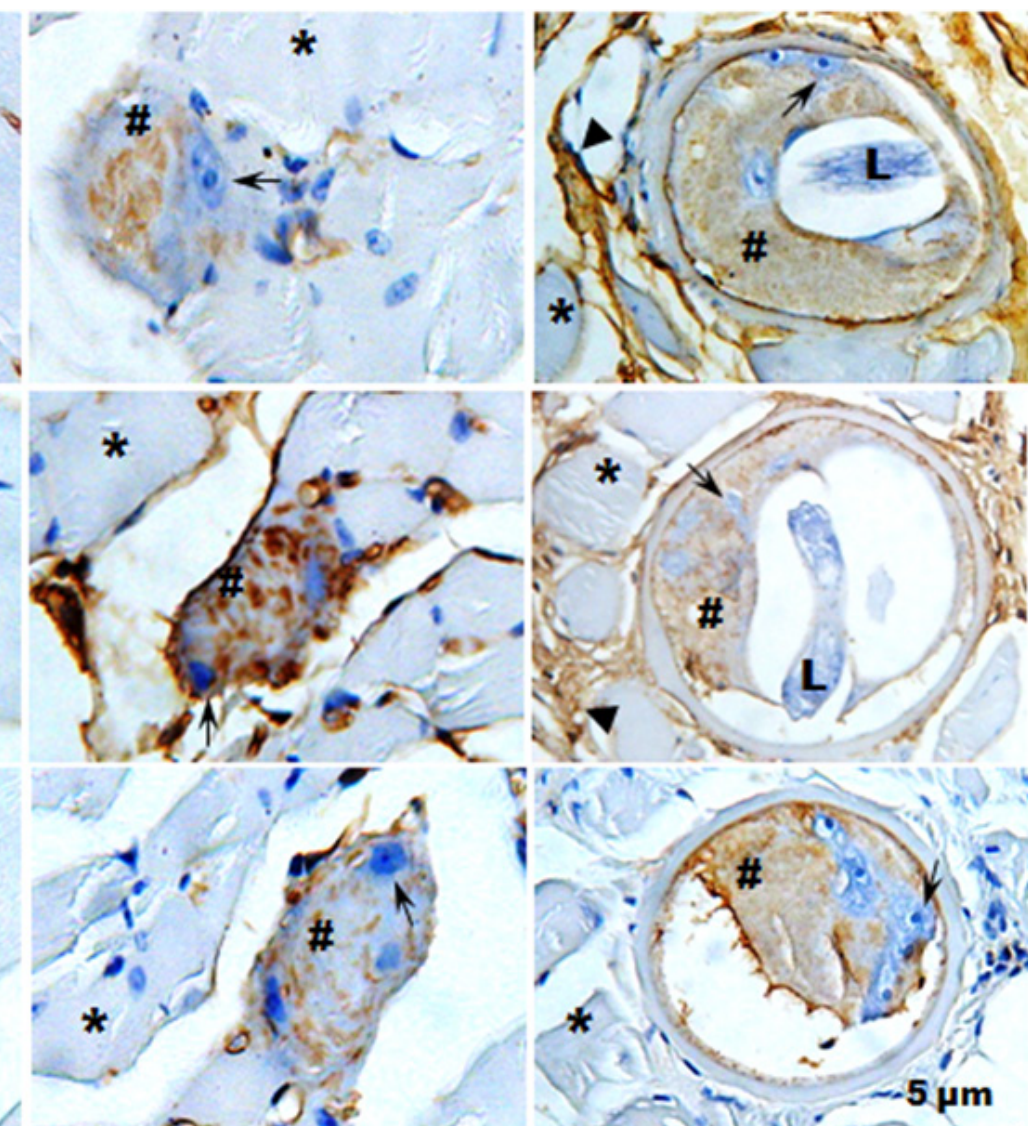

Fig. 2. Lectin histochemistry on mouse skeletal muscles with Trichinella spiralis at 10, 14 and 40 days post invasion (d.p.i.). Formalin fixed sections were stained with biotinylated lectins Maackia amurensis lectin-II (MAL-II), Sambucus nigra agglutinin (SNA) and Tritrichomonas mobilensis lectin (TML). Note: brown colour - positive histochemical reaction; hash tag - occupied sarcoplasm; star - non-occupied skeletal muscle fibre; arrow - enlarged nucleus; block arrow - blood vessels or interstitial connective tissue; L - larva. Hematoxylin and eosin (H\&E), streptavidin-biotin peroxidase, 3,3'-diaminobenzidine (DAB). 

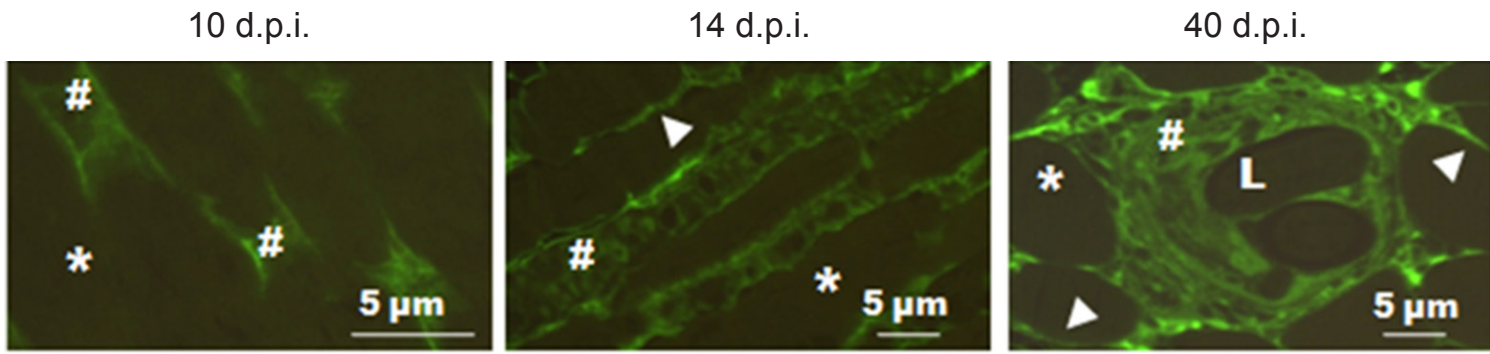

Fig. 3. Fluorescent lectin histochemistry on mouse skeletal muscles with Trichinella spiralis at 10, 14 and 40 days post infestation (d.p.i.) Modified methacarn fixed sections were stained with fluorescein-labelled Sambucus nigra agglutinin. Note: fluorescent green colour - positive histochemical reaction; hash tag - occupied sarcoplasma; star - non-occupied skeletal muscle fibre; block arrow - blood vessels or interstitial connective tissue; L - larva.

Table 2. Evaluation of the intensity of intracellular staining within the skeletal muscle fibres occupied by Trichinella spiralis after application of sialic acid specific lectins with different linkage specificity, with and without neuraminidase pretreatment (Neu), or after pre-incubation with oligosaccharides.

\begin{tabular}{lccc}
\hline \multirow{2}{*}{ Lectin } & \multicolumn{3}{c}{ Days post infection } \\
\cline { 2 - 4 } & 10 & 14 & 40 \\
\hline MAL & + & ++ & ++ \\
MAL-Neu & - & + & - \\
MAL-3'-sialyllactose & - & - & - \\
MAL-6'-sialyllactose & + & ++ & ++ \\
SNA & ++ & ++ & ++ \\
SNA-Neu & - & + & ++ \\
SNA-3'-sialyllactose & ++ & +++ & ++ \\
SNA-6'-sialyllactose & - & - & - \\
SNA-fluorescein conj. & + & + & + \\
TML & + & ++ & ++ \\
TML-Neu & - & - & - \\
TML-3'-sialyllactose & - & + & + \\
TML-6'-sialyllactose & + & + & + \\
\hline
\end{tabular}

MAL - Maackia amurensis lectin-II; SNA - Sambucus nigra agglutinin; TML - Tritrichomonas mobilensis lectin. The results were interpreted as negative $(-)$ and weak $(+)$, moderate $(++)$ and strong $(+++)$ positive. The results from the staining with fluorescein labelled SNA were interpreted as negative (-) and positive (+).

sialic acid or sialyltransferase activity between the control and infected samples.

When necessary, the data were transformed to arbitrary units and the trend lines were plotted together with the percentage of invaded skeletal muscle fibres or nurse cells.

\section{RESULTS}

\section{Histology of the process of de-differentiation of the affected skeletal muscle fibres after invasion by Trichinella spiralis}

For the particular time points chosen for the present study, no accumulation of cells of inflammatory response was observed around the areas of occupation by the larvae of Trichinella spiralis (Fig. 1). The occupied sites in skeletal muscle specimens from 10 d.p.i. were distinguished by the enlargement and centralisation of nuclei of the fibre. On 14 and 16 d.p.i. the affected area of the sarcoplasm became progressively disintegrated and by 40 d.p.i. the de-differentiation of the occupied fibre resulted in a nurse cell completion. During this period the affected sarcoplasm changed from eosinophilic to basophilic and then back to light eosinophilic. The enlarged nuclei persisted also in the complete nurse cell containing coiled larvae. The invaded muscle fibres at all investigated time points were labelled by the rabbit hyperimmune serum against infectious larvae of $T$. spiralis (Fig. 1) indicating the presence of larval excretory-secretory products within the sarcoplasm and enlarged nuclei. The surrounding non-affected areas remained unstained (Fig. 1). In all histological sections examined throughout this study, including the sections submitted for histochemistry, the nurse cells in all stages of development remained integrated within the surrounding healthy fibres.

\section{Lectin histochemistry of healthy and invaded mouse skeletal muscle}

In healthy skeletal muscle fibres the three biotinylated lectins (TML, MAL and SNA) labelled the blood vessels and the interstitial connective tissue but not the sarcoplasm (Fig. 2); the sarcolemma was labelled by the fluorescent SNA (Fig. 3). The worm did not show any reactivity with the lectins (Figs. 2, 3).

All lectins showed reactivity within the affected sarcoplasm during the whole process of muscle cell transformation including the cytoplasm of the mature nurse cell (Table 2, Figs. 2, 3). The intensity of the staining of the sarcoplasm with all lectins increased progressively with the time course of nurse cell formation (Table 2, Figs. 2, 3).

Preincubation of MAL with 3'-sialyllactose and of SNA with 6'-sialyllactose resulted in a complete block of lectin activity (Table 2). TML activity was partially inhibited by both 3'- and 6'-sialyllactose (Table 2). The pretreatment of the sections with neuraminidase resulted in a complete absence of TML staining in sections from all time points of the study, confirming the high specificity of the lectin; the staining with SNA and MAL was only reduced (Table 2).

\section{Estimation of the levels of free and bound sialic acid and the total sialyltransferase activity in healthy and invaded skeletal muscle tissue}

The level of the unbound sialic acid progressively increased in the time course of development of the nurse cell (Fig. 4A1) and the amount of sialylated glycoproteins was also elevated, most prominently at day 16 p.i. (Fig. 4B1). The total activity of sialyltransferases also increased, most 

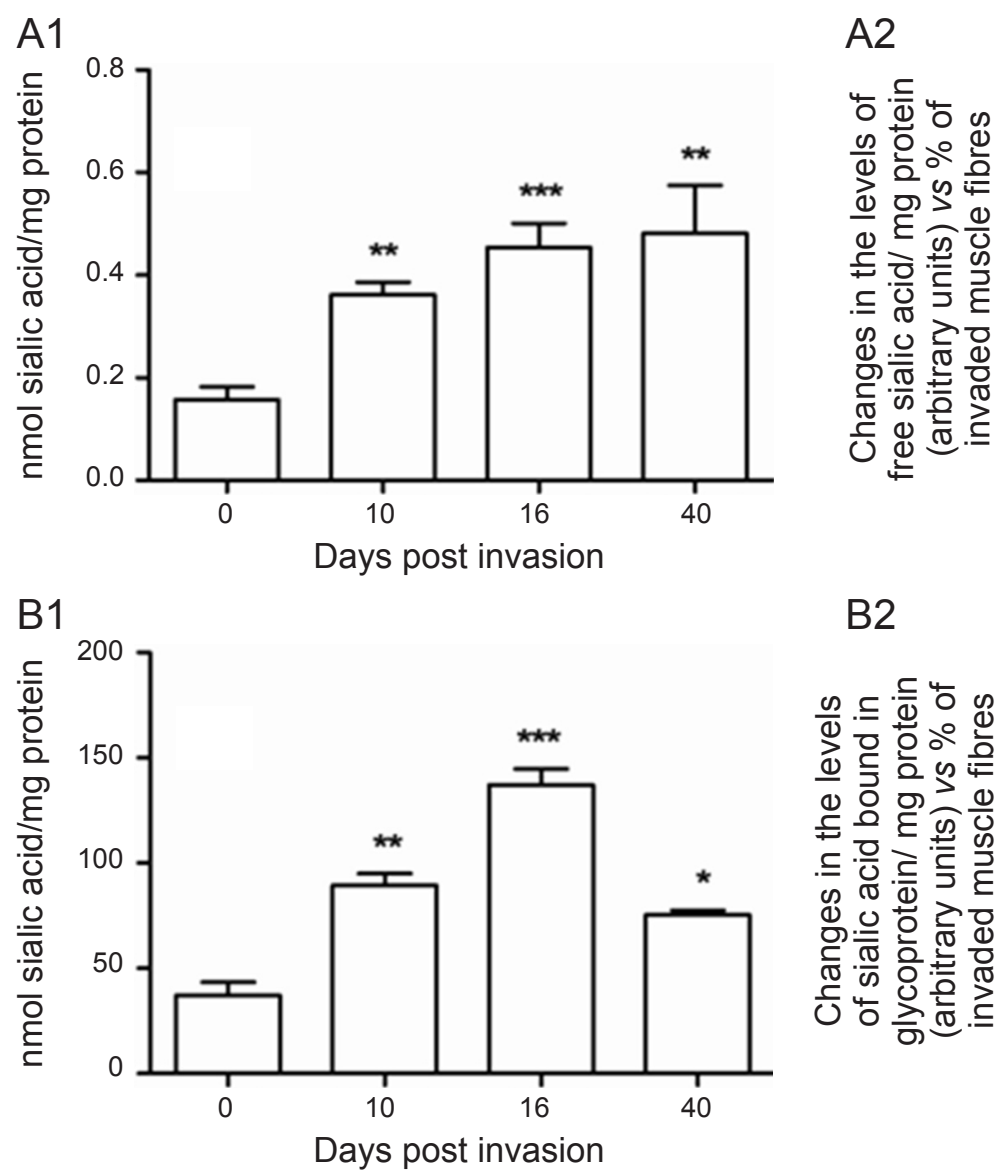

B2
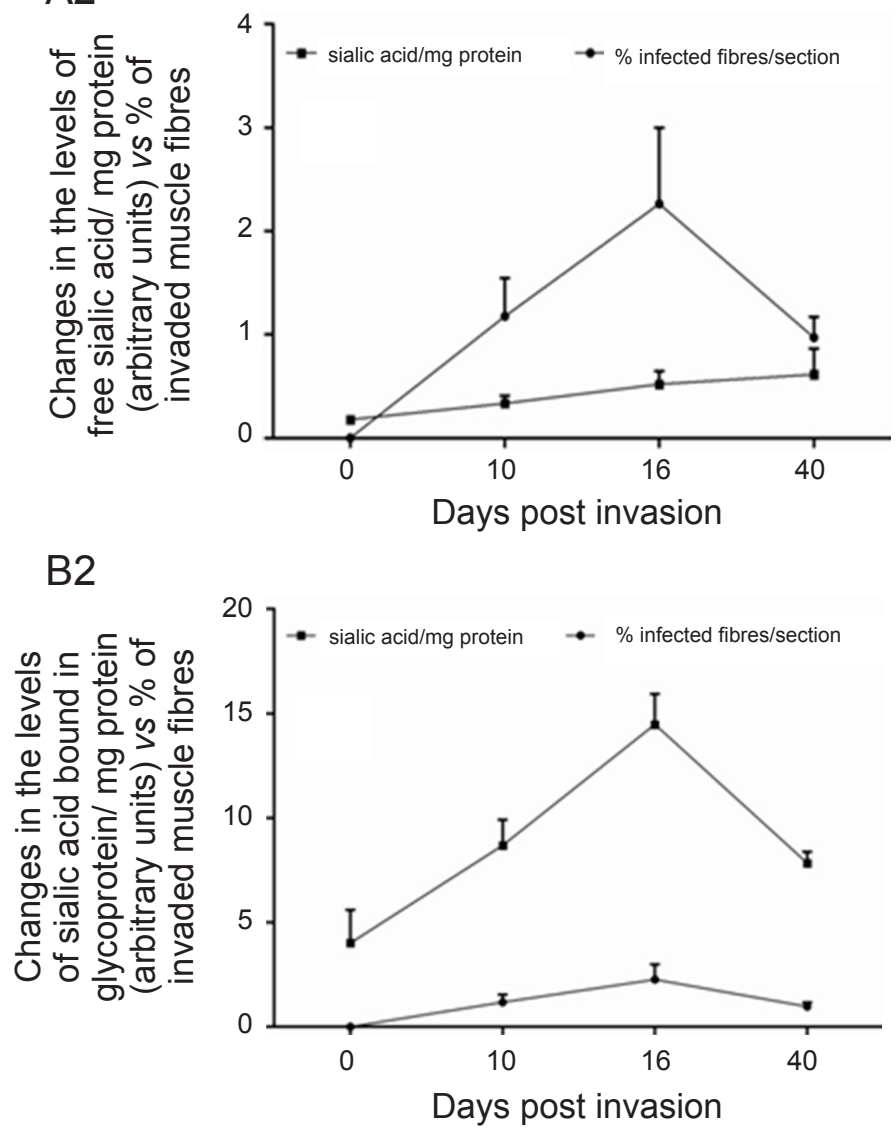

Fig. 4. Estimation of unbound sialic acid (A1) and the sialic acid bound in glycoproteins (B1) in mouse skeletal muscle tissue in the time course of development of the nurse cell of Trichinella spiralis. The relation between the changes in the quantities of sialic acid and the percentage of invaded muscle fibres is also presented (A2 and B2). The bars represent the mean values with SD of 12 reactions and tissue sections $(n=12)$ per group. The stars indicate statistically significant difference between the invaded tissues in progress versus healthy skeletal muscle used as a control: $* * * \mathrm{P}<0.001$, $* * \mathrm{P}<0.01, * \mathrm{P}<0.05$.

A

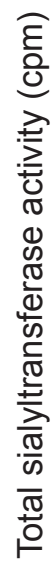

B

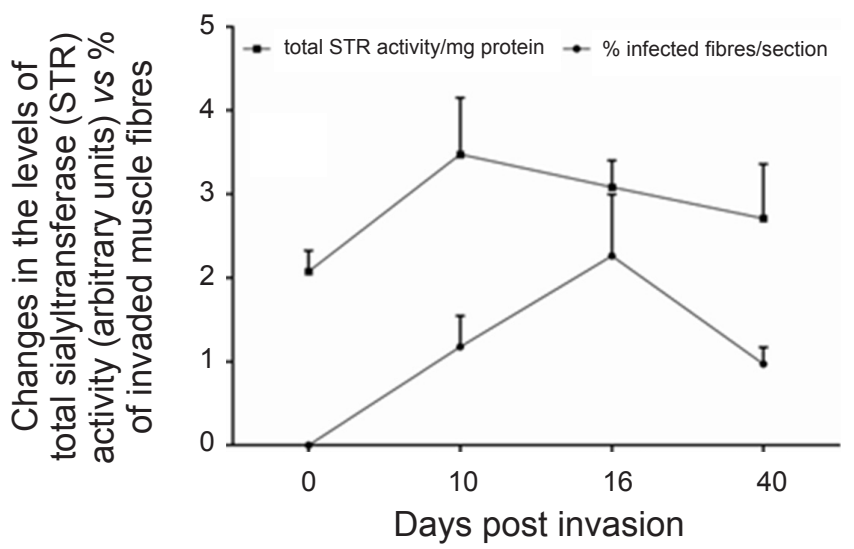

Fig. 5. Estimation of total sialyltransferase activity in mouse skeletal muscle tissue in the time course of development of the nurse cell of Trichinella spiralis (A). The relation between the changes in the sialyltransferase activity and the percentage of invaded muscle fibres is also presented (B). The bars represent the mean values with SD of twelve reactions and tissue sections $(\mathrm{n}=12)$ per group. The stars indicate statistically significant difference between the invaded tissues in progress versus healthy skeletal muscle used as a control: $* * * \mathrm{P}<0.001, * * \mathrm{P}<0.01, * \mathrm{P}<0.05$.

significantly at day 10 p.i. (Fig. 5). The estimated levels of sialic acid and the total sialyltransferase activity changed proportionally with the percentage of invaded muscle fibres (Figs. 4A2,B2, 5B). 


\section{DISCUSSION}

In this work, using the experimental model of mouse skeletal muscle fibres invaded by the parasitic nematode Trichinella spiralis for the first time, we report the elevated intracellular accumulation of $\alpha-2,3$ - and $\alpha-2,6$-sialylated glycoconjugates. These findings are supported by our additional data on increased levels of free and protein-bound sialic acid, as well as an enhanced total sialyltransferase activity. It had been concluded that larvae of Trichinella did not show preference for any particular type of muscle fibre (fast or slow twitch) (Ochoa and Pallis 1980). In our observations we also did not detect differences in the intensity of the sialic acid specific lectins staining within the invaded fibres. Thus, it is evident that after being attacked by the nematode, all fibres start to express similar pattern of reaction.

Little is known about the sialylated glycoproteins from skeletal muscle tissue and most of the data are related to disease conditions. A recent study showed that different types of sialic acid decorate glycosylated molecules present in the sarcolemma and in the sarcoplasm, which vary in young and aged muscle (Marini et al. 2014). One of the well-studied sialylated glycoproteins from skeletal muscle fibre is $\alpha$-dystroglycan, which is a part of the dystrophin-associated glycoprotein complex (DGC) (Ervasti and Campbell 1993). This glycoprotein bears a high abundance of sialylated core 1 structures (Sia- $\alpha-2,3-G a l-$ $\beta-1,3-G a l N A c-S e r / T h r)$ as well as an uncommon sialylated O-mannosyl oligosaccharide (Sia- $\alpha-2,3-\mathrm{Gal}-\beta-1,4-\mathrm{Gl}$ cNAc- $\beta$-1,2-Man-Ser/Thr) (Sasaki et al. 1998). Its aberrant glycosylation is associated with several congenital muscle diseases in humans, including Fukuyama-type congenital muscular dystrophy, muscle-eye-brain disease and Walker-Warburg syndrome (Barresi and Campbell 2006). Hyposialylation of the oligosaccharide chains of $\alpha$-dystroglycan is their common pathological feature (Hayashi et al. 2001, Michele et al. 2002). The distorted glycosylation of the DGC component $\alpha$-dystroglycan results in reduced binding to basal lamina components and loss in structural stability of muscle. These changes also substantially affect the function of the satellite cells (Ross et al. 2012), which reside between the basal lamina and sarcolemma and represent the key stem cells responsible for muscle repair. The satellite cells actively participate in the process of nurse cell formation (Matsuo et al. 2000) and it is likely that the increased sialylation reported in our work is playing a significant role in support of this process.

The bifunctional enzyme UDP-N-acetylglucosamine 2-epimerase/M-acetylmannosamine kinase (GNE) is vital in the $\mathrm{N}$-acetylneuraminic acid biology (Eisenberg et al. 2001). It catalyses two serial reactions of conversion of UDP-N-acetylglucosamine to mannose-6-phosphate and thus initiates the biosynthesis of $\mathrm{N}$-acetylneuraminic acid (Hindrelich et al. 1997). Up-regulation of GNE mRNA and protein were recently reported in mouse skeletal muscle fibres after chemically-induced injury and in regenerat- ing fibres (Nakamura et al. 2010). The presence of polysialylated form of Neural Cell Adhesion Molecule was also reported in regenerating muscle fibres after chemically-induced injury (Figarella-Branger et al. 1999). An increased level of protein bound sialic acid was found in denervated fast twitch (Andrew and Appel 1973, Cotrufo and Appel 1973) but not in slow twitch muscles (Cotrufo and Appel 1973).

The intense intrafibre distribution of the sialylated glycoconjugates is another intriguing feature of the phenomenon described in our work since in healthy fibres they are apparently present in very low concentrations. The parasitic origin of these glycans is unlikely since $T$. spiralis does not synthesise sialic acids (Morelle et al. 2000, Gruden-Movsesijan et al. 2002, Milcheva et al. 2009a,b). Hence, it is tempting to hypothesise that the increased sialic acid presentations in all secondary impairments of skeletal muscle fibres mentioned above, our findings including, maintain the compact character of the damaged areas. This assumption is supported by the observation that even if skeletal muscle tissue expresses relatively low levels of GNE in comparison to other tissues (Horstkorte et al. 1999), the skeletal muscles are apparently very sensitive to losses of sialic acid as illustrated by the resulting inherited disease known as distal myopathy with rimmed vacuoles or hereditary inclusion body myopathy (Tajima et al. 2005, Broccolini et al. 2011).

It is known that sialylated glycoconjugates are the carriers of negative external charge when expressed on the membranes so that the increased level of O-linked glycosylation with terminally linked sialic acid might modulate the gating of voltage-gated potassium channels (Schwetz et al. 2011). Such changes in ion channel activity will lead to altered action potential waveforms and thereby modulate excitability, which might be an important condition for successful accommodation of the parasite in the muscle fibre.

In conclusion, we can sum up with the statement that the presence of the parasitic nematode $T$. spiralis in the cross striated muscle initiates glycosylation changes with increased sialic acid expression within the affected area of the muscle fibre. This might affect the activity of satellite cells and the contractility of the muscle in the way to favour the successful accommodation of the parasite in the host cell. Our future investigations will focus on the type and the structure of these carbohydrate chains, and on identification of their protein carriers and the particular sialyltransferases involved in this phenomenon.

Acknowledgements. The authors express sincere gratitude to Mrs. Emilia Klincová for her excellent technical assistance. This work was partially supported by the Slovak Research and Development Agency (grant APVV - 0282 - 11) and by the European Social Fund and Republic of Bulgaria, Operational Programme 'Development of Human Resources' 2007-2013 (grant No. BG051PO001-3.3.06-0048 from 04.10.2012). 


\section{REFERENCES}

AminofF D. 1961: Methods for the quantitative estimation of $\mathrm{N}$-acetylneuraminic acid and their application to hydrolysates of sialomucoids. Biochem. J. 81: 384-392.

Andrew C., Appel S.H. 1973: Macromolecular characterization of membranes: 1. Proteins and sialic acid of normal and denervated muscle. J. Biol. Chem. 248: 5156-5163.

Babál P., Pindak F.F., Wells D.J., Gardner W.A. 1994: Purification and characterization of a sialic acid-specific lectin from Tritrichomonas mobilensis. Biochem. J. 299: 341-346.

BARRESi R., CAMpBell K.P. 2006: Dystroglycan: from biosynthesis to pathogenesis of human disease. J. Cell Sci. 119: 199-207.

Broccolini A., Gidaro T., De Cristofaro R., Morosetti R., Gliubizzi C., Ricci E., Tonali P.A., Mirabella M. 2008 Hyposialylation of neprilysin possibly affects its expression and enzymatic activity in hereditary inclusion-body myopathy muscle. J. Neurochem. 105: 971-981.

Broccolini A., Gidaro T., Morosetti R., Sancricca C., MiRABELLA M. 2011: Hereditary inclusion-body myopathy with sparing the quadriceps: the many tiles of an incomplete puzzle. Acta Myol. 30: 91-95.

CApó V., Despommier D.D. 1996: Clinical aspects of infection with Trichinella spp. Clin. Microbiol. Rev. 9: 47-54.

Combs A.C., ERvasti J.M. 2005: Enhanced laminin binding by alpha-dystroglycan after enzymatic deglycosylation. Biochem. J. 390: 303-309.

Cotrufo R., Appel S.H. 1973: Effects of denervation on glycoproteins of rabbit grastrocnemius and soleus muscle. Exp. Neurol. 39: 58-69.

Cox M.L., Schray C.L., Luster C.N., Stewart Z.S., Korytko P.J., Khan K.N.M., Paulauskis J.D., Dunstan R.W. 2006 Assessment of fixatives, fixation, and tissue processing on morphology and RNA integrity. Exp. Mol. Pathol. 80: 183-191.

DesPommier D.D. 1998: How does Trichinella spiralis make itself home? Parasitol. Today 14: 318-323.

Eisenberg I., Avidan N., Potikha T., Hochner H., Chen M., Olender T., Barash M., Shemesh M., Sadeh M., GrabovNardini G., Shmilevich .I, Friedmann A., Karpati G., Bradley W.C., Baumbach L., Lancet D., Asher E.B., Beckmann J.S., Argov Z., Mitrani-Rosenbaum S. 2001: The UDP-N-acetylglucosamine 2-epimerase/N-acetylmannosamine kinase gene is mutated in recessive hereditary inclusion body myopathy. Nature Genet. 29: 83-87.

Ervasti J.M., Campbell K.P. 1993: A role for the dystrophin-glycoprotein complex as a transmembrane linker between laminin and actin. J. Cell. Biol. 122: 809-823.

Figarella-Branger D., Pellisier J.F., Bianco N., Karpati G. 1999: Sequence of expression of MyoD1 and various cell surface and cytoskeletal proteins in regenerating mouse muscle fibers following treatment with sodium dihydrogen phosphate. J. Neurol. Sci. 170: 151-160.

Gruden-Movsesijan A., Ilic N., Sofronic-Milosavlievic L. 2002: Lectin-blot analyses of Trichinella spiralis muscle larvae excretory-secretory components. Parasitol. Res. 88: 1004-1007.

Hanisch F., Weidemann W., Grossmann M., Joshi P.R., Holzhausen H.J., Stoltenburg G., Weis J., Zierz S., Horstkorte R. 2013: Sialylation and muscle performance: Sialic acid is a marker of muscle ageing. PLoS ONE 8: e80520.

Hayashi Y.K., Ogawa M., Tagawa K., Noguchi S., Ishihara T., Nonaka I., Arahata K. 2001: Selective deficiency of $\alpha$-dystroglycan in Fukuyama-type congenital muscular dystrophy. Neurology 57: 115-12.

Hinderlich S., Stache R., Zeitler R., Reutter W. 1997: A bifunctional enzyme catalyzes the first two steps in $\mathrm{N}$-acetylneuraminic acid biosynthesis in rat liver: purification and characterization of the UDP-N-acetylglucosamine 2-epimerase/N-acetylmannosamine kinase. J. Biol. Chem. 272: 2431324318.
Horstkorte R., Nohring S., Wiechens N., Schwarzkopf M., Danker K., Retter W., Lucka L. 1999: Tissue expression and amino acid sequence of murine UDP-N-acetylglucosamine-2-epimerase/N-acetylmannosamine kinase. Eur. J. Biochem. 260: 923-927.

Johnson D., Montpetit M.L., Stocker P.J., Bennett E.S. 2004: The sialic acid component of the $\beta$ subunit modulates voltage-gated sodium channel function. J. Biol. Chem. 279: 44303-44310.

Kaku H., Kaneko H., Minamihara N., Iwata K., Jordan E.T., Rojo M.A., Minani-Ishii N., Minami E., Hisajima S. ShibuYA N. 2007: Elderberry bark lectins evolved to recognize Neu5Ac $\alpha 2,6 \mathrm{Gal} / \mathrm{GalNAc}$ sequence from a Gal/GalNAc binding lectin through the substitution of amino-acid residues critical for the binding to sialic acid. J. Biochem. 142: 393-401.

Kapel C.M.O., GAmble H.R. 2000: Infectivity, persistence, and antibody response to domestic and sylvatic Trichinella spp. in experimentally infected pigs. Int. J. Parasitol. 30: 215-221.

Knibbs R.N., Goldstein I.J., Ratcliffe R.M., Shibuya N. 1991: Characterization of the carbohydrate binding specificity of the leucoagglutinating lectin from Maackia amurensis. Comparison with other sialic acid-specific lectins. J. Biol. Chem. 266: 83-88.

Komandarev S., Mihov L., Hovorka I. 1986: Immunological studies on different Trichinella species. I. Antigenic characterization by means of linear immunoelectrophoresis. Helminthologia 21: 13-19.

Marini M., Ambrosini S., Sarchielli E., Thyrion G.D.Z. Bonaccini L., Vannelli G.B., Sgambati E. 2014: Expression of sialic acids in human adult skeletal muscle tissue. Acta Histochem. 116: 926-935.

Matsuo A., Wu Z., Nagano I., Takahashi Y. 2000: Five types of nuclei present in the capsule of Trichinella spiralis. Parasitology 121: 203-210.

McDearmon E.L., Combs A.C., Ervasti J.M. 2003: Core 1 glycans on $\alpha$-dystroglycan mediate laminin-induced acetylcholine receptor clustering but not laminin binding. J. Biol. Chem. 278: 44868-44873.

Michele D.E., Barresi R., Kanagawa M., Saito F., Cohn R.D., Satz J.S., Dollar J., Nishino I., Kelley R.I., Somer H., Straub V., Mathews K.D., Moore S.A., Campbell K.P. 2002: Post-translational disruption of dystroglycan-ligand interactions in congenital muscular dystrophies. Nature 418: $422-425$.

Milcheva R., Petkova S., BabÁl P. 2009a: Detection of Oglycosylated proteins from different Trichinella species muscle larvae total extracts. Helminthologia 46: 139-144.

Milcheva R.S., Petkova S.L., Dubinský P., Hurniková Z., BABÁL P. 2009b: Glycosylation changes in different developmental stages of Trichinella. Biologia 64: 180-186.

Morelle W., Haslam S.M., Morris H.R., Dell A. 2000: Characterization of the N-linked glycans of adult Trichinella spiralis. Mol. Biochem. Parasitol. 109: 171-177.

Nakamura K., Tsukamoto Y., Hijiya N., Higuchi Y., Yano S., Yokoyama S., Kumamoto T., Moriyama M. 2010: Induction of GNE in myofibers after muscle injury. Pathobiology 77 : 191-199.

OchoA J., PAllis C. 1980: Trichinella thrives in both oxidative and glycolytic human muscle fibres. J. Neurol. Neurosurg. Psychiatry 43: 281-282.

Ross J., Benn A., Jonuschies J., Boldrin L., Muntoni F., HeWitT J.E., Brown S.C., Morgan J.E. 2012: Defects in glycosylation impair satellite stem cell function and niche composition in the muscles of the dystrophic large (myd) mouse. Stem Cells 30: 2330-2341.

Sasaki T., Yamada H., Matsumura K., Shimizu T., Kobata A., Endo T. 1998: Detection of O-mannosyl glycans in rabbit 
skeletal muscle $\alpha$-dystroglycan. Biochim. Biophys. Acta 1425: 599-606.

SCHAUER R. 2004: Sialic acids: fascinating sugars in higher animals and man. Zoology 107: 49-64.

Schauer R. 2009: Sialic acids as regulators of molecular and cellular interactions. Curr. Opin. Struct. Biol. 19: 1-8.

Schwetz T.A., Norring N.A., Ednie A.R., Bennett E.S. 2011: Sialic acids attached to $O$-glycans modulate voltage-gated potassium channel gating. J. Biol. Chem. 286: 4123-4132.

SEFARINI-CESSI F. 1977: Sialyltransferase activity in regenerating rat liver. Biochem. J. 166: 381-386.

Tajima Y., Uyama E., Go S., Sato C., Tao N., Kotani M., Hino H., Suzuki A., Sanai Y., Kitajima K., Sakuraba H. 2005

Received 9 February 2015

Accepted 1 July 2015
Distal myopathy with rimmed vacuoles: impaired O-glycan formation in muscular glycoproteins. Am. J. Pathol. 166: 1121-1130.

Traving C., Schauer R. 1998: Structure, function and metabolism of sialic acids. Cell. Mol. Life Sci. 54: 1330-1349.

VARKI A. 1997: Sialic acids as ligands in recognition phenomena. FASEB J. 11: 248-255.

WARREN L. 1959: The thiobarbituric acid assay of sialic acids. J. Biol. Chem. 234: 1971-1975.

Yao K., Ubuka T., Masuoka N., Kinuta M., Ikeda T. 1989: Direct determination of bound sialic acids in sialoglycoproteins by acidic ninhydrin reaction. Anal. Biochem. 197: 332-335.

Cite this article as: Milcheva R., Ivanov D., Iliev I., Russev R., Petkova S., Babál P. 2015: Increased sialylation as a phenomenon in accommodation of the parasitic nematode Trichinella spiralis in skeletal muscle fiber. Folia Parasitol. 62: 049. 